\title{
Correction to: Effective Multimodal Opinion Mining Framework Using Ensemble Learning Technique for Disease Risk Prediction
}

\author{
V. J. Aiswaryadevi, S. Kiruthika, G. Priyanka, N. Nataraj, and M. S. Sruthi
}

\section{Correction to:}

Chapter "Effective Multimodal Opinion Mining Framework Using Ensemble Learning Technique for Disease Risk

Prediction" in: S. Smys et al. (eds.),

Inventive Computation and Information Technologies, Lecture

Notes in Networks and Systems 173, https://doi.org/10.1007/978-981-33-4305-4_67

In the original version of chapter 67, the following belated correction has been incorporated: The author name "G. S. Priyanka" has been changed to "G. Priyanka". The chapter and book have been updated with this change. 